\title{
FRAY TOMÁS DE TORQUEMADA, ICONÓGRAFO Y PROMOTOR DE LAS ARTES
}

\author{
POR \\ Sonia CABALlero EscAmilla \\ Universidad de Salamanca
}

\begin{abstract}
En este trabajo se analiza la ascendencia del inquisidor Torquemada sobre dos fundaciones, el convento de Santo Tomás de Ávila y el de Santa Cruz de Segovia. El contexto histórico en el que surgen y su vinculación con la actividad inquisitorial las convierte en soportes de un mensaje hábilmente diseñado por el fraile dominico en el que pone de manifiesto el prestigio de la Orden de Santo Domingo y la implicación de la Monarquía en la lucha antiherética. Aprovechando la eficacia propagandística del lenguaje plástico, no dudará en acudir a fórmulas iconográficas del pasado adaptándolas a su momento presente, creando el caldo de cultivo necesario para lograr su objetivo, la expulsión de los judíos.
\end{abstract}

Palabras clave: Santo Tomás de Ávila; Santa Cruz de Segovia: "Iconógrafo"; Propaganda; Topos; Exempla; "Sostén"; Sermones; Herejías; Deicidas; Alboraique.

In this study the author analyses the Inquisitor Torquemada's role in two Dominican foundations: the monasteries of Santo Tomás in Ávila and Santa Cruz in Segovia. The historical context in which they emerged and their association with inquisitorial activities converted them into ideal supports for a message designed by this Dominican friar for the purpose of conveying the prestige of the Order and the involvement of the Monarchy in the struggle against heretics. He used the arts to convey a propagandistic message, adapting older iconographic formulas to his current needs, aimed at promoting the expulsion of the Jews.

Key words: Santo Tomás de Ávila; Santa Cruz de Segovia; "Iconographer"; Propaganda; Topos; Exempla; "Sostén"; Sermons; Heresy; Deicidas (Murderers of Christ); Alboraique.

Fray Tomás de Torquemada ha pasado a la Historia en su faceta de inquisidor y como uno de los hombres de mayor confianza de los Reyes Católicos ${ }^{1}$. Junto a su indudable protagonismo en la esfera social y política, nuestra intención es abordar su papel como promotor de las artes y asiduo usuario del lenguaje plástico como importante instrumento de propaganda y eficaz expositor

${ }^{1}$ SuÁReZ FernándeZ, Luis: "Dimensiones religiosas en Isabel la Católica", Catálogo de la exposición Isabel la Católica. La magnificencia de un reinado, Valladolid, 2004, p. 54. 
de su programa político-religioso. Por este motivo, se le puede calificar de iconógrafo, entendido aquí no desde el punto de vista de quien se dedica al estudio de las imágenes y su simbolismo, sino como diseñador de un programa ${ }^{2}$. Su personalidad y carrera eclesiástica está vinculada a dos fundaciones próximas en el espacio y el tiempo, el convento de Santa Cruz de Segovia y el de Santo Tomás de Aquino en Ávila, a los que dedicaremos nuestra atención en las próximas páginas. Pero a fray Tomás le corresponde un calificativo más, el de promotor, puesto que no sólo buscó la financiación de las obras, sino que promovió su ejecución y se implicó directamente en la adecuación de su forma y contenido. A pesar de que proporcionó mucha hacienda, joyas, oro, plata y ornamentos... alcanzó de los Reyes Católicos otras muchas cosas que bastaban para enriquecerla ${ }^{3}$. Cierto es que la totalidad de los recursos económicos empleados no provenían directamente de sus arcas sino de los Reyes Católicos y los bienes confiscados a los judíos en su mayor parte, pero la promoción artística no consiste únicamente en financiar sino en buscar los medios necesarios y en impulsar, alentar y dirigir. Por otro lado, según los cronistas, las donaciones efectuadas por los Reyes Católicos se hacían con el fin de agradecer a Torquemada sus servicios porque no quiere ser pagado ni remunerado en otras dignidades y prelacías ${ }^{4}$. Esto quiere decir que los beneficios económicos que podía recibir gracias a su actuación junto a los Reyes, los desviaba hacia las fundaciones que dirigía. Se podría hablar, por tanto, de promoción económica indirecta.

\section{Apuntes biográficos}

Su carrera eclesiástica se inició en el convento de San Pablo de Valladolid, pero será a raíz de su nombramiento como prior de Santa Cruz de Segovia, cuando su nombre ocupará las páginas de nuestra Historia, ya que en esos años se convertirá en confesor regio y, posteriormente, en 1483 , en inquisidor general.

Las crónicas le presentan como un hombre austero, de fuerte personalidad y preocupado, prácticamente obsesionado, por el problema de la heterodoxia religiosa. Su carácter le llevaría a "dirigir" las decisiones de los Reyes en esta materia ${ }^{5}$. De hecho, él mismo exigió a los monarcas una prohibición para que los judíos no ejercieran oficios públicos y no les fueran cedidas rentas reales:

...que los judios no tengan entre los cristianos oficios públicos ni los Reyes no los cedan sus rentas salario con muy estrechas condiciones las quales no se guardan a q vra alteza debe mandar que a ningund judio sean dadas rentas reales y muy menos treinta por $q$ es grand retondo y mengua 6 .

El clima religioso que se vivía en Segovia, donde gran parte de la población se había convertido al cristianismo, distaba de la situación patente en Ávila, que destacaba por ser una de las

\footnotetext{
2 Siguiendo la distinción establecida por el profesor Serafín Moralejo en Formas elocuentes. Reflexiones sobre la teoría de la representación, Madrid, 2004, p. 11.

${ }^{3}$ Fray Joan López: Tercera parte de la historia general de Sancto Domingo y de su orden de predicadores, Valladolid, 1613.

4 Ibidem.

${ }^{5}$ En varias ocasiones envió informes a los monarcas que influirían de forma muy directa en sus decisiones, como el titulado Las cosas que debian remediar los Reyes, caracterizado por una gran dureza.

${ }^{6}$ Archivo del Convento de Santo Tomás de Ávila: Cajón Sagrada Forma/Torquemada: Fotocopia del Memorial del prior de Santa Cruz al Rey [tachado] Católica sobre tres cossas, sobre los offos regidores de las cibdades y villas y sobre los judios y sobre los blasphemos hechizeros y adevinos. El original se conserva en el Archivo General de Simancas: Diversos de Castilla, leg. 1. Exp. n. ${ }^{\circ} 78$.
} 
ciudades con más de la mitad de los habitantes practicantes del judaísmo. Así lo hace constar Gonzalo Chacón en una carta de 1474 escrita a los Reyes: la mayor parte de la población de Ávila es de judios ${ }^{7}$.

Su nombramiento como Inquisidor General y el establecimiento del Tribunal en el convento de Santo Tomás de Ávila, le permitió centrarse en un único objetivo, la erradicación de las herejías. Contaba con un precedente en el cargo, Pedro de Arbués, inquisidor de la Corona de Aragón, asesinado a manos de unos herejes en Zaragoza, en pleno ejercicio de sus funciones. Las condiciones dramáticas de su muerte fueron manipuladas para provocar un cambio en las opiniones generales de la población: del rechazo más absoluto al establecimiento del Santo Oficio, pasaron al odio más acérrimo hacia los supuestos responsables de una muerte tan cruel, los judíos. Una situación que se repetiría en Ávila, aunque con una víctima diferente. A raíz del asesinato del Santo Niño de La Guardia y del Auto de Fe celebrado en Ávila en 1491, la actitud pacífica de la población giró hacia un comportamiento más violento contra los judíos, a los que se acusaba del infanticidio ritual. El inquisidor hizo uso, de este modo, de lo que se podría considerar un topos de la facción social antijudaica, en nuestras fronteras y fuera de ellas, responsabilizar a la población judía de asesinatos rituales de niños. Se puede incluso aplicar la etiqueta de fenómeno historiográfico con graves consecuencias. El primer caso medieval hay que retrotraerlo al s. XII y vincularlo con la muerte del joven William en Norwich en 1144. A raíz de este hecho apareció una obra escrita The life and miracles of St. William of Norwich, de Thomas de Monmouth. Este autor había llegado a ser prior de la catedral de Norwich y escribió el texto años después de que aconteciera el supuesto crimen, tras hablar con los testigos de la historia. Supo por boca de uno de ellos, el judío converso Teobaldo, que todos los años líderes de los judíos de España se reunían en Narbona donde preparaban su sacrificio anual. Allí decidían al azar el país en el que se iba a llevar el ritual ese año. Todos estos datos nos permiten concluir que el caso del Santo Niño de La Guardia es un eslabón más de toda una tradición historiográfica anterior que tenía por fin desprestigiar a los judíos ${ }^{8}$. Torquemada aprovechó la situación, valiéndose además de todo un escenario plástico, con actores encargados de legitimar y justificar los principios propugnados por la Inquisición y destinados, a su vez, a influir en las opiniones de los fieles cristianos 9 . Santo Tomás sería el principal centro de movimientos, donde desplegó un conjunto de imágenes, pictóricas y escultóricas, cuya función queda expresada. Sus armas fueron las mismas que se utilizaban en el ejercicio de la predicación, es decir, una instrucción gráfica unida al sermón hablado. Las imágenes actúan, de ese modo, como materializaciones del contenido de sus discursos y sirven, a su vez, de exempla.

\footnotetext{
7 León Tello, Pilar: Judios de Ávila, Ávila, 1963, p. 21.

${ }^{8}$ Existen dos casos de este tipo en la Antigüedad; en el siglo II el historiador Posidonio acusaba a los judíos de canibalismo. En el siglo V el historiador Sócrates recoge la historia del maltrato de un niño en la cruz a cargo de unos judíos en torno a 415. Gavin I. LANGMUIR: "Historiographic crucifixion", Les juifs au regard de l'Histoire. Mélanges en l'honneur de Bernhard Blumenkranz, París, 1985, pp. 109-127. La devoción al Santo Niño de La Guardia persiste hasta bien entrado el siglo XVI, de hecho, Juan de Borgoña le dedicó un retablo en La Guardia (Toledo) en 1532, poco después de morir Fonseca. Para más detalles, Mateo, Isabel: Juan de Borgoña, Madrid, 2005.

${ }^{9}$ Me refiero a las representaciones escultóricas de la portada de la iglesia, así como a las pinturas que presidieron sus altares. Cada una de las escenas representadas, personajes y atributos fueron elegidos por Torquemada como modelos que apostillaban su elaborado mensaje. Para más detalles CABALLERo EsCAMILLA, Sonia: "Iconografía del prestigio: la escultura monumental del convento de Santo Tomás de Ávila en el contexto inquisitorial hispano", actas del Congreso Internacional Sujetos, conceptos y prácticas de poder en la Edad Media hispana, Murcia, 2007, pp. 395-412. Idem: "El convento de Santo Tomás de Ávila: Santo Tomás de Aquino, Santo Domingo de Guzmán y San Pedro Mártir, adalides de la propaganda inquisitorial", actas del Congreso Internacional Isabel la Católica y su época, Madrid, 2007, pp. 12831311; Idem: "Las sargas de Pedro Berruguete en el Museo del Prado, eslabones de un mensaje inquisitorial", Boletín del Museo e Instituto "Camón Aznar", n. ${ }^{\circ}$ 101, 2008, pp. 7-30.
} 


\section{La Santa Cueva de Segovia}

El título de Prior del convento de Santa Cruz de Segovia debió de tener una especial significación para él puesto que lo mantuvo en vida, incluso después de ser nombrado Inquisidor General y de trasladar su residencia a Ávila.

Segovia era una ciudad de especial importancia para la orden dominica, ya que, según la tradición, allí había predicado su fundador, Santo Domingo de Guzmán. Además, extramuros de la ciudad, existía una Cueva en la que supuestamente el Santo se había mortificado, lo que dio origen a una primera y humilde fundación en el s. XIII, bastante deteriorada cuando Torquemada se puso a la cabeza del monasterio en el $\mathrm{s}$. XV. Las condiciones de conservación del edificio motivaron una reforma del complejo, dirigida por el nuevo prior a partir de $1474^{10}$. Desde este momento, los paralelismos existentes entre el edificio segoviano y el convento abulense se constatarán en varios aspectos, desde la propia financiación, en la que contaron con el respaldo de los Reyes Católicos ${ }^{11}$, pasando por la tipología arquitectónica y el diseño de los distintos programas iconográficos que los completaban.

Las características arquitectónicas de ambas fábricas nos hablan de la intervención de arquitectos con una formación toledana. Según la documentación conservada de la catedral segoviana, en Santa Cruz trabajaron artistas del entorno de Juan Guas, activo en Segovia desde $1472^{12}$. Dadas las estrechas similitudes arquitectónicas entre el convento de Santo Tomás y el de Santa Cruz, sobre todo en lo que al abovedamiento se refiere, Eduardo Carrero ha propuesto la teoría de un arquitecto común a ambas construcciones ${ }^{13}$. Tenemos documentada la autoría de Martín de Solórzano en las trazas de la iglesia de Santo Tomás de Ávila y en otras de la capital abulense ${ }^{14}$. Aunque hasta el momento desconocemos dónde transcurre su etapa de aprendizaje, la relación estilística de sus obras con el área toledana le sitúa muy probablemente en esta zona.

Torquemada fue el responsable de las nuevas obras arquitectónicas, pero también de las escultóricas y pictóricas. No sólo eligió a los artistas, sino que, conocido el uso y significado de las imágenes, también proyectó los programas iconográficos de las obras plásticas.

Junto a la cabecera de la iglesia se sitúa la Santa Cueva, muy reformada tras la época barroca. Lo que más nos interesa para este estudio es la capilla que le sirve de acceso levantada en tiempos de los Reyes Católicos. Se trata de un único espacio rectangular cubierto con una gran bóveda estrellada, del mismo tipo que las que cubren las naves de las iglesias de Santa Cruz o Santo Tomás en Ávila, lo que nos lleva a pensar en la intervención de Solórzano también en esta zona. Apoya en ménsulas decoradas con distintos motivos, escudos de la Orden, ángeles con

10 Sobre la evolución constructiva, CARRERo SANTAmaría, Eduardo: "El convento de Santa Cruz la Real de Segovia. De los orígenes románicos a la fábrica tardogótica”, Boletín del Museo e Instituto “Camón Aznar”, n. ${ }^{\circ}$ XCI, 2003, pp. 143-163.

${ }^{11}$ En las dos fundaciones los Reyes Católicos cedieron rentas procedentes de incautaciones a los judíos y de los acusados por delitos de herejías. Fue uno de los aspectos resaltados por Jerónimo Münzer en su Viaje a España: ... creo que los edificios de esta naturaleza se costean principalmente de los bienes de los marranos, que eran los más ricos de España entera, y de los convictos de herejía, condenados al fuego, de cuyos bienes se apoderaba el fisco real... Checa Cremades, Fernando: "Isabel I de Castilla: los lenguajes artísticos del poder", Catálogo de la exposición Isabel la Católica..., op. cit., p. 23.

12 Hernández, A.: "Juan Guas, maestro de obras de la catedral de Segovia (1472-1491), Boletín del Seminario de Estudios de Arte y Arqueología, XIII, 1946-1947, p. 81.

13 Carrero Santamaría, Eduardo: "La iglesia del Monasterio de Santa Cruz la Real de Segovia a fines del siglo XV. Una confluencia de modelos en la arquitectura tardogótica castellana", Anuario de la Universidad Internacional SEK, n. ${ }^{\circ}$ 5, 1999, pp. 77-97.

${ }^{14}$ Martínez Frías, José M.: "Contribución al estudio de la obra de Martín Ruiz de Solórzano en Ávila", Boletín del Museo e Instituto “Camón Aznar”, n. . LXXXIX, 2002, pp. 197-271. 
yugos y flechas o bien las iniciales de los Reyes Y o F, atributos del fundador, como un báculo, lirios, o perros luchando contra lobos (fig. 1). Es decir, se apuesta por una figuración en la que se ha buscado presentar una unión entre Monarquía y Orden dominica, al tiempo que se canta la victoria de los domini canes sobre los lobos de la herejía. Indudablemente fue Torquemada quien dio indicaciones precisas sobre los temas a representar. Los mismos contenidos que hizo plasmar en la portada de la iglesia de sus conventos en Segovia y Ávila como veremos: la idea del triunfo de la Iglesia y, concretamente, de los dominicos sobre los movimientos heréticos y la implicación de la Monarquía en esa causa.

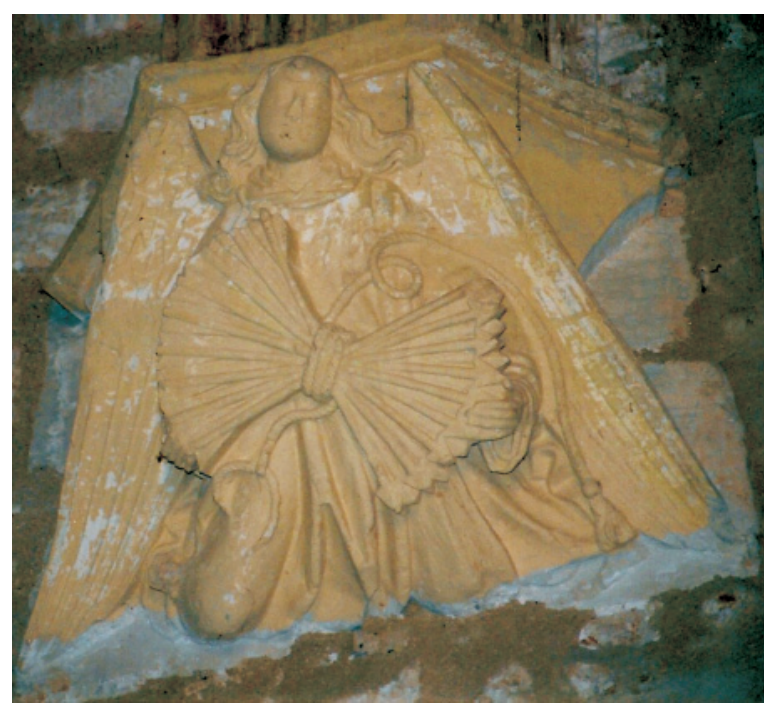

Fig. 1. Ménsula. Ángel con el haz de flechas. Capilla de la Santa Cueva. Convento de la Santa Cruz. Segovia.

La portada despliega un curioso programa ya analizado por Eduardo Carrero, a cuyo artículo remito para evitar repeticiones innecesarias ${ }^{15}$. No obstante, un importante detalle ha pasado desapercibido a la crítica hasta el momento. Las alusiones a la pareja real, en este caso sus iniciales y sus brazos sosteniendo la cruz, vendrían a ratificar la implicación directa de los Reyes en la causa antiherética dirigida por la Orden de Santo Domingo (fig. 2). Así se deduce del propio epígrafe que rodea la portada: Pues Dios con los Santos, a vos Reyes, iguala en el tener mandados favoresçer su Fe católica los dos ${ }^{16}$. Pero se enfatiza, aún más, por la iconografía elegida. La Cruz, símbolo del triunfo cristiano, está sostenida por los brazos de los Reyes Católicos y Santo Domingo, situado detrás. Nos encontramos ante una imagen del "sostén" con un simbolismo reconocido, y ampliamente documentado, en el mundo cristiano. El éxito de esta iconografía habría que retrotaerlo a los inicios del cristianismo con la escena relatada en el Éxodo, en que Moisés levanta las manos para asegurar la victoria en la batalla contra los Amalecitas, cuya primera representación conocida data del siglo V en Santa María la Mayor de Roma ${ }^{17}$ :

15 Carrero Santamaría, Eduardo: "Patrocinio regio e Inquisición. El programa iconográfico de la cueva de Santo Domingo en Santa Cruz la Real de Segovia", Gil de Siloé y la escultura de su tiempo, Actas del Congreso Internacional (Burgos, 13-16 de octubre de 1999), centro cultural "Casa del Cordón”, Burgos, 2001, pp. 447-462.

${ }^{16}$ Ibidem.

17 Shapiro, Meyer: Les mots et les images, París, 2000, p. 46. 


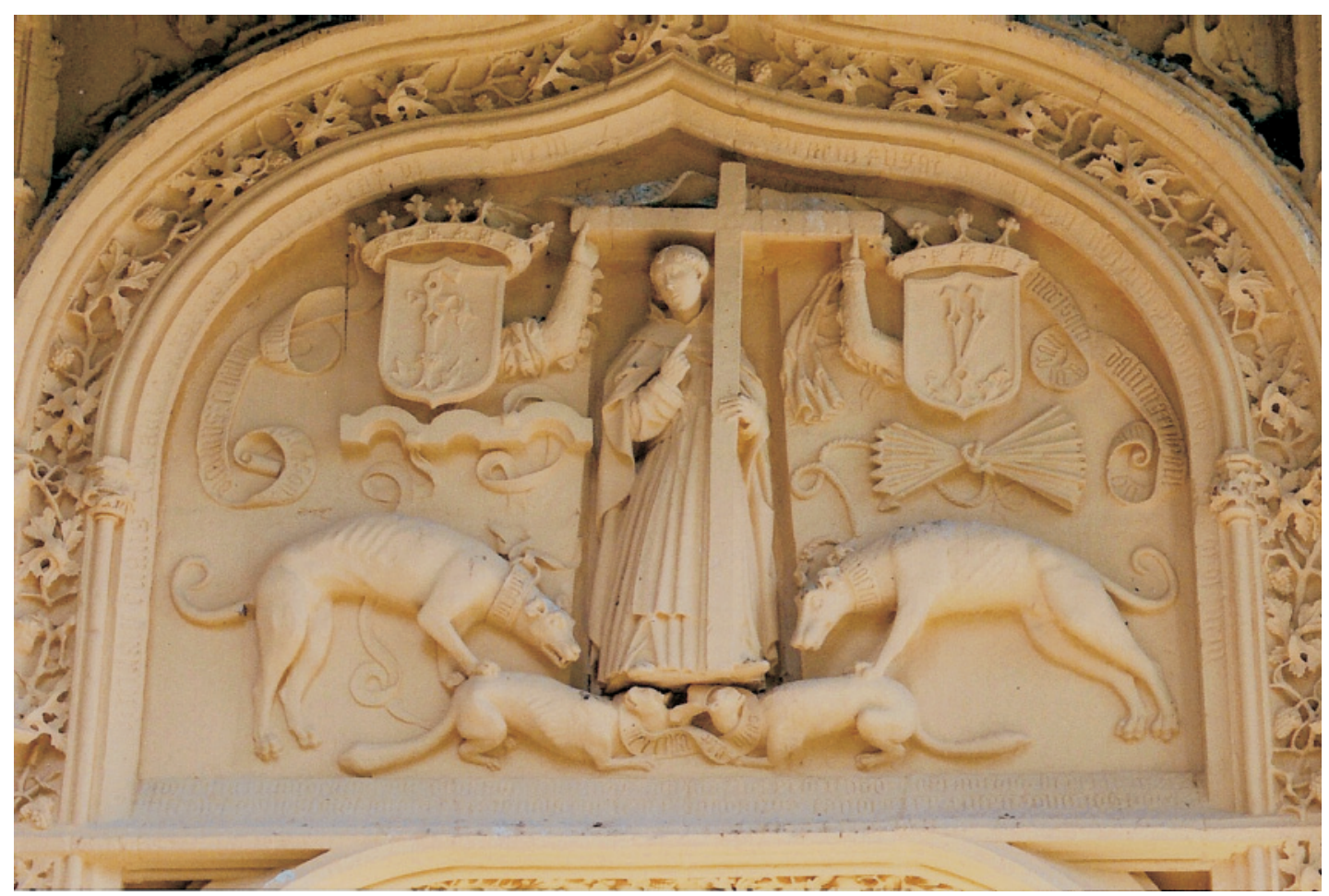

Fig. 2. Portada de la Santa Cueva. Convento de Santa Cruz de Segovia.

Josué hizo como le había ordenado Moisés, y luchó contra Amalec. Moisés, Aarón y Jur subieron a la cima de la colina. Y aconteció que cuando Moisés tenía sus brazos alzados vencía Israel, y cuando los bajaba vencía Amalec. Mas como se le cansaban los brazos a Moisés, tomaron una piedra y se la pusieron debajo. Él se sentó encima, y Aarón y Jur le sostenían los brazos, uno a cada lado. De este modo los brazos de Moisés se sostuvieron en alto hasta la puesta del sol. Josué derrotó a Amalec y a su ejército a filo de espada. (Éxodo 17, 10-14).

Con los brazos levantados en plena batalla, repitiendo la postura de Jesús en la cruz, Moisés se convertirá en su símbolo. Con el tiempo, se enriquecerá con la presencia de dos personajes a un lado y otro, Aarón y Jur que sostendrán los brazos de Moisés frente a la batalla y será este gesto el que conceda la victoria frente al enemigo de la Fe de $\mathrm{Cristo}^{18}$. En el caso segoviano se ha recurrido a una imagen-tipo, muy utilizada en el mundo medieval para expresar la idea de triunfo con intermediarios, pero con otros protagonistas. La Cruz, símbolo del cristianismo, personificada por Moisés en los ejemplos anteriores, es sostenida por los brazos de la autoridad regia -haciendo las veces de Aarón y Jur-, con la presencia también de Santo Domingo de Guz-

\footnotetext{
18 Casualmente, las primeras representaciones de este tema iconográfico enriquecido con la presencia de Aarón y Jur sosteniendo los brazos de Moisés, comienzan en el momento en que el Papa Urbano predica la Cruzada contra los infieles, reforzando, de este modo, la interpretación que aquí presentamos. Schapiro, Meyer: Les mots..., op. cit., p. 55.
} 
mán detrás de la cruz ${ }^{19}$. A sus pies tiene lugar la batalla entre los defensores de la fe y la herejía, simbolizados por los perros y lobos. La tradición de los predicadores como perros del señor, está ya en la base de los relatos hagiográficos. En un Códice conservado en el convento de Santo Domingo el Real de Madrid compuesto por textos de carácter litúrgico y leyendas de varios santos dominicos ${ }^{20}$, Santo Domingo es presentado como un noble predicador que traya en la boca encendida de buena palabra con que encendiesse conplido amor...e que allongasse los lobos de las ovejas con ladridos de su predicación... ${ }^{21}$. La victoria aquí cantada será de la Iglesia, con la intermediación de los Reyes Católicos y la Orden de los dominicos. Por tanto, como ya manifestó el profesor Yarza ${ }^{22}$, estamos en condiciones de admitir que las imágenes de los Reyes vendrían a exaltar y sobre todo a prestigiar la Inquisición, más que una referencia a su intervención directa en la obra, como ocurrirá en Santo Tomás de Ávila.

La imagen real se hace explícita en la misma entrada a la iglesia del convento de Santa Cruz. Presidiendo el tímpano, el grupo de la Piedad compuesto por las figuras de la Virgen, Cristo, un Santo Varón y la Magdalena, se encuentra situado entre las estatuas orantes de los Reyes Católicos, acompañados a su vez de Juan el Evangelista, en el caso de Fernando, y San Juan Bautista junto a Isabel. Conocida la devoción de la Reina por el tema de la Quinta Angustia y el éxito de esta iconografía en el contexto espiritual del momento, dentro y fuera de nuestras fronteras, no extraña su presencia aquí. Las prácticas devocionales transmitidas por la Devotio Moderna basadas en un tipo de oración íntima, en la lectura, meditación y recreación mental de los pasajes leídos, generan un modelo iconográfico como el que vemos aquí: figuras de místicos, fieles y donantes arrodillados, con el libro en sus manos o a sus pies, frente a una imagen real, que les sirve de apoyo visual a sus meditaciones, o imaginaria, presentando así el contenido de su visiones mentales $^{23}$. Pero, el éxito de la Piedad y del grupo que constituye el tema de las Lamentaciones sobre el cuerpo de Cristo durante el s. XV en toda Europa, es equiparable al culto surgido en torno al sacramento de la Eucaristía ${ }^{24}$. La expansión de las herejías y el número de adeptos en muchas de ellas, condujo a la exaltación del principal dogma de la religión católica y, a su vez, el

19 Se trataba de una fórmula conocida tanto por los cristianos como por los hebreos. Una representación de Moisés con los brazos sostenidos por Aarón y Jur forma parte de un manuscrito hebreo del siglo XIII (British Museum, Add. Ms. 11639, fol. $525 \mathrm{v}^{\circ}$ ), aunque lógicamente se ha variado la posición de los brazos abiertos -alegoría de la cruz- por un gesto de plegaria con las manos juntas. El interés radica en la representación de una iconografía común a los dos grupos receptores con el fin de que fuera comprensible para ambos.

${ }^{20}$ Sobre el uso litúrgico del códice madrileño, CÁtedra, Pedro M.: Liturgia, poesía y teatro en la Edad Media, Madrid, 2005. En cuanto a las repercusiones artísticas de este tipo de material, un avance en CABALLERo EsCAMILLA, Sonia: "El Códice Medieval como fuente artística: Berruguete en Santo Tomás de Ávila", Libros con Arte. Arte con Libros, Cáceres, 2007, pp. 147-159.

${ }^{21}$ Archivo del Convento de Santo Domingo el Real de Madrid. Códice. F. VI v. ${ }^{\circ}$ Un Códice similar, aunque escrito en latín por corresponder a una comunidad masculina, debió de encontrarse en su momento en la biblioteca del convento de Santo Tomás de Ávila. Puesto que Torquemada fue el iniciador de la misma, debemos pensar que pudo tratarse de una donación suya. Caballero Escamilla, Sonia: "El Códice Medieval...", op. cit.

22 YARZA LuACES, Joaquín: "Imágenes reales hispanas en el fin de la Edad Media", 23 Semana de Estudios Medievales de Estella, 22-26 de julio de 1996; Poderes públicos en la España medieval: principados, reinos y coronas, Pamplona, 1997, p. 465.

${ }^{23}$ Veánse los siguientes estudios al respecto; Post, R. R.: The Modern Devotion. Confrontation with Reformation and Humanism (Studies in Medieval and Reformation Thought, 3), Leiden, 1968; HARBISON: "Visions and meditations in early Flemish painting”, Simiolus, 15, 1985, pp. 87-118. RINGBOM, Sixten: Les images de dévotion XII ${ }^{e}-X V^{\circledR}$ siécle, París, 1995. CABALLERO Escamilla, Sonia: "La imagen femenina y la Devotio Moderna", en Feminismo ecológico. Estudios multidisciplinares de género, Salamanca, 2007, pp. 141-169.

${ }^{24}$ Un estudio general sobre el tema de la Piedad en YARZA LuACES, Joaquín: "El arte borgoñón en España y la imagen de la Piedad", Catálogo de la exposición Humanismo y Reforma en el s. XVI, Valencia, del 2-10-2002 al 151-2003, pp. 53-60. 
más discutido. La proliferación de temas como la Misa de San Gregorio o las leyendas surgidas sobre Sagradas Formas sangrantes, robos y ataques por parte de judíos, la convierten en el principal exponente de la ortodoxia religiosa. A fin de cuentas, el grupo de la Virgen con Cristo sobre sus rodillas, constituye un ejemplo más de la veneración por el cuerpo de Cristo. Es la Madre quien, sobre sus rodillas, ofrece el cuerpo de su Hijo al fiel. De ahí que ocupe las tablas centrales en los bancos de los retablos, es decir, el lugar sacramental por excelencia. En un auténtico best seller de la literatura espiritual del siglo XV, como es la Vita Christi de Ludolfo de Sajonia, se establece una relación entre el momento en que Cristo es bajado de la Cruz y la Comunión:

... es en efecto mucho más importante recibir el Cuerpo de Cristo del altar del sacrificio que del descenso de la cruz del sacrificio porque los que le descendieron le recibieron en sus brazos y sus manos, mientras que los demás le reciben en su boca y en su corazón ${ }^{25}$.

En resumidas cuentas, el hecho de que el grupo de la Piedad, acompañado por las figuras orantes de los Reyes Católicos, centre la fachada de un edificio, cuya iconografía pregonaba la unión de las dos facciones más importantes de la sociedad, la Iglesia con los dominicos a su cabeza, y los Reyes, en la lucha contra quienes abjuraban de la fe en Jesucristo, apunta en un sentido que va más allá de constituir un mero trasunto visual de la nueva espiritualidad: se trata de la exaltación del cuerpo de Cristo, venerado por los más altos representantes de la sociedad, los Reyes, y dispuesto, a su vez, para recibir el culto de los fieles que asistían a las predicaciones públicas. Por otro lado, el carácter dramático del momento, provocaría un sentimiento doble: de compasión hacia la Madre y de odio hacia los responsables de semejante dolor, los judíos. Las imágenes se complementarían con las glosas de los frailes en sus predicaciones.

\section{Santa Cruz de Segovia y Santo Tomás de Ávila, escaparates de la propaganda inquisitorial}

En el lado más próximo a la ciudad, la iglesia del convento de Santa Cruz se abre a un atrio, como suele ser habitual en los conventos de las órdenes mendicantes. Construidos en función de su actividad principal, la predicación, se abrían a amplias plazas en las que tenían lugar los sermones públicos. De este modo, las portadas actuaban como un fondo de los discursos verbales y las imágenes allí desplegadas ratificaban el contenido de los sermones ${ }^{26}$.

La identidad de temas elegidos en las portadas de ambos conventos confirma una misma personalidad al frente de su diseño, fray Tomás de Torquemada. Los márgenes del acceso están ocupados por la representación escultórica de los protagonistas de la Orden, Santo Domingo de Guzmán, San Pedro de Verona, Santo Tomás de Ávila y San Vicente Ferrer ${ }^{27}$. Junto a ellos, otros

25 BeLting, Hans: L'Image et son public au Moyen Âge, París, 1998, p. 105.

${ }^{26}$ Consúltense algunos ejemplos en SÁnChez AmeiJeIras, Rocío: "Discursos y poéticas en la escultura gótica leonesa del s. XIII", Actas del Congreso Internacional La catedral de León en la Edad Media (León, 7-11 de abril de 2003), León, 2004, pp. 203-241. Y para las iglesias mendicantes gallegas, el artículo de la misma autora "Espiritualidad mendicante e iconografía gótica gallega", Semata, 1996, pp. 333-353.

27 Eduardo Carrero ha sido quien ha identificado a San Vicente Ferrer en la portada segoviana. También ha señalado la condición de Torquemada como iconógrafo, CARRERo SANTAMARÍA, Eduardo: "Un panegírico de la predicación. La Exaltación de la Cruz y la iconografía de los Dominicos en Segovia" Actas del Simposium Internacional Pedro Berruguete y su entorno, Palencia 24, 25 y 26 de abril de 2003. Diputación de Palencia, 2004, pp. 361-370. Pero nadie, hasta ahora, ha señalado la presencia de San Vicente Ferrer en la portada de Santo Tomás de Ávila. Caballero Escamilla, Sonia: "Iconografía del prestigio...", op. cit. 
santos que destacaron en la labor de la predicación y por su condición de mártires. En Segovia sólo quedan las peanas vacías, pero sí se han conservado en Ávila, y es muy probable que fueran los mismos: San Juan Bautista y Evangelista y Santa Catalina de Siena frente a su homónima de Alejandría $^{28}$. Ambas portadas se utilizaron como verdaderos expositores en los que se canta la gloria de la Orden, mediante sus principales protagonistas que destacaron en la defensa de la fe católica frente a las herejías. Se trataba de establecer vínculos con la situación presente, en la que se estaba luchando contra la expansión del judaísmo, a cuyos seguidores se les calificaba como deicidas. La transposición al momento histórico en el que vive Torquemada viene de la mano de los Reyes Católicos, cuyos emblemas e imágenes presiden ambas portadas ${ }^{29}$, pero también con la representación de San Vicente Ferrer, un dominico que, sólo unos años antes, había destacado por ser un ferviente defensor de la causa cristiana y el responsable de la conversión de gran parte de la población judía de Castilla $^{30}$ (fig. 3). El objetivo en uno y otro caso era el mismo, legitimar la represión inquisitorial dirigida por Torquemada mediante las raíces prestigiosas del pasado. De ese modo, presentándolos como exempla en los sermones, mediatizaba la mentalidad popular creando un clima de apoyo a su causa.

Uno de los atributos vinculados aquí a Santo Domingo de Guzmán, repetidos en las dos portadas de las iglesias segoviana y abulense, en uno de los retablos pintados por Pedro Berruguete para uno de los altares colaterales de Santo Tomás de Ávila, e incluso, en una de las vidrieras del crucero, es la imagen del fundador clavando el báculo sobre un animal con formas caninas ardiendo en llamas ${ }^{31}$ (figs. 4 y 5). De este modo, aunque no fue así históricamente, se implica al fundador en una lucha directa contra los herejes, y muy concretamente, los falsos conversos.

En mi opinión, el origen de esta iconografía habría que ponerlo en relación con la literatura coetánea y, en este sentido, aparecieron durante la época de represión inquisitorial diversos libros con la finalidad de ayudar a los inquisidores en su persecución a los judíos, así como otros en los que se fustiga al converso acusándoles de hipocresía y falsa fe de una forma despiadada ${ }^{32}$. El más interesante, desde nuestro punto de vista, es el conocido como Libro o Tratado del Alboraique. Nació con una clara intención de provocar odio en un clima de fuerte antisemitismo. Su cronología no es segura pero es aceptada generalmente la de $1488^{33}$. Dado el abundante número de expresiones hebraicas que aparece, se ha considerado que su autor debió de ser alguien que conoció muy de cerca la situación de los conversos. Incluso pudo tratarse de un converso, y no sería extraño en el contexto histórico de la época puesto que durante el siglo XV aparecen varios textos, muchos escritos por conversos, en los que se recomienda dureza en el trato contra los

28 En los flancos laterales del acceso se representan las figuras del arcángel San Gabriel y la Virgen María, conformando la escena de la Anunciación, es decir, una alusión directa al comienzo de la Redención, con todo lo que ello implica en el contexto que estamos tratando. Caballero Escamilla, Sonia: "Iconografía del prestigio...", op. cit.

${ }_{29}$ Actualmente el tímpano de la iglesia de Santo Tomás de Ávila está liso, pero probablemente, en su origen, estuvo ocupada por un grupo similar al que preside el acceso a la iglesia de Santa Cruz en Segovia.

${ }^{30}$ Sobre la labor de San Vicente Ferrer, destacaremos los siguientes estudios, MilLÁs, J. M.: "San Vicente Ferrer y el antisemitismo", Sefarad X, 1950, pp. 182-185. Idem.: "En torno a la predicación judaica de San Vicente Ferrer", Boletín de la Real Academia de la Historia, CXLII, 1958. CÁtedra, P. M.: Sermón, sociedad y literatura en la Edad Media. San Vicente Ferrer en Castilla (1411-1412), Salamanca, 1994.

${ }^{31}$ El análisis iconográfico sobre la tabla de Berruguete conservada en el Museo del Prado, se puede consultar en Yarza Luaces, Joaquín: "Una imagen dirigida: los retablos de Santo Domingo de Guzmán y San Pedro de Mártir de Pedro Berruguete", Historias Inmortales, Barcelona, 2002, p. 39; CABAllero Escamilla, Sonia: "El convento de Santo Tomás de Ávila: Santo Tomás de Aquino...”, op. cit.

${ }^{32}$ Ya desde el s. XIII aparecieron escritos antijudíos en Castilla. VALdEÓn BARUQue, Julio: Judíos y conversos en la Castilla medieval, Valladolid, 2004, p. 46.

33 Bustamante García, Agustín: “Alboraique. Un dato iconográfico”, Archivo Español de Arte, n. ${ }^{\circ}$ 280, 1997, p. 420. 


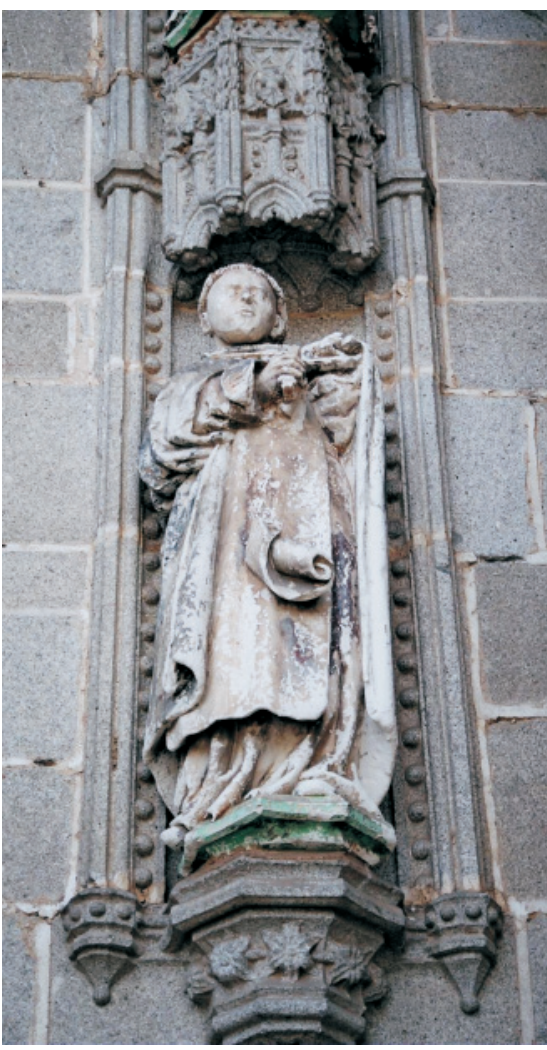

Fig. 3. San Vicente Ferrer. Portada de la iglesia del Convento de Santo Tomás de Ávila.

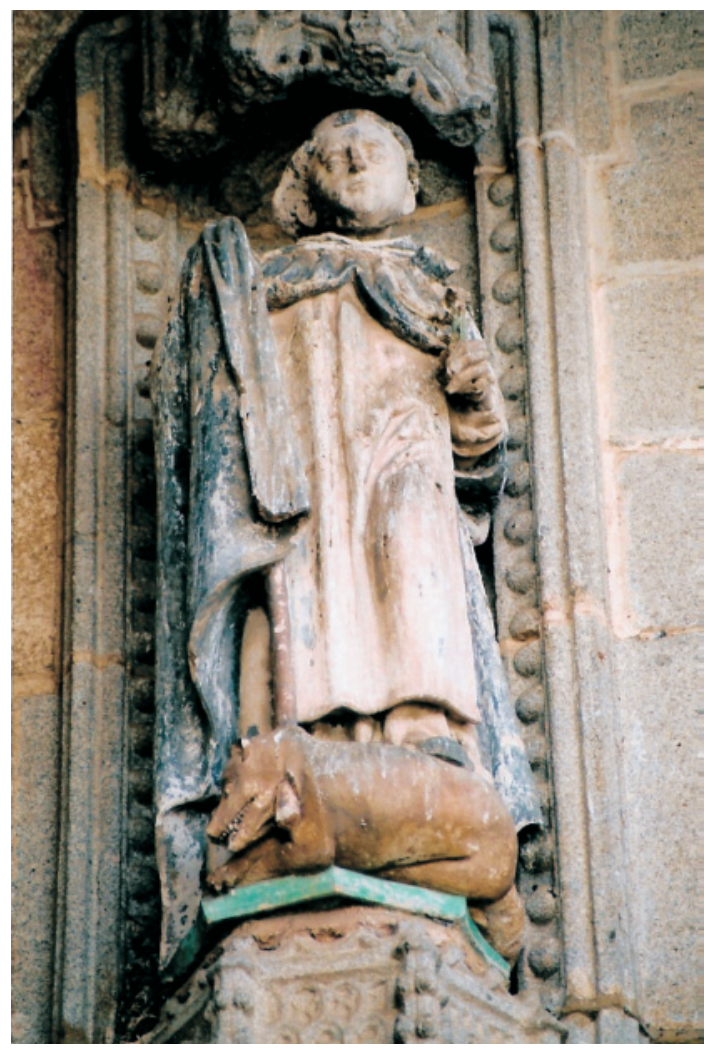

Fig. 4. Santo Domingo de Guzmán. Portada de la iglesia del Convento de Santo Tomás de Ávila.

judaizantes, considerándoles responsables de la actitud recelosa del resto de la población contra los conversos en general. Es el caso de Alonso de Espina y su Fortalitium fidei (1459), Alonso de Oropesa Lumen ad revelationem gentium (1465), otros fueron utilizados en las frecuentes disputas dialécticas entre ambos grupos, como Diálogos contra los judíos de Pedro Alfonso ${ }^{34}$, en la disputa de Barcelona en 1263 y en la de Tortosa en 1413-1414 ${ }^{35}$. Textos presentes en las bibliotecas reales, como es el caso de la infanta D. ${ }^{a}$ Blanca que ordenó la traducción de varios escritos del converso Abner de Burgos (1270-1340) al castellano, en los que atacaba a sus antiguos correligionarios ${ }^{36}$. Los Reyes Católicos, y en concreto la Reina, poseían un ejemplar del Cancionero de Juan Alfonso de Baena ${ }^{37}$, la Declaración sobre la herejía de Andrés de Miranda, el tratado Contra haereticam pravitatem de Gonzalo de Villadiego o las Quastiones disputatae

34 Judío convertido al cristianismo en 1106 que utilizó los escritos hebreos para luchar contra su antigua fe.

35 Tena, Pedro: "Una versión incunable hispana de los Diálogos contra los judios de Pedro Alfonso, Sefarad, año 57. Fasc. 1, Madrid, 1997, pp. 179-194.

36 SÁEnz Badillos, Ángel: Literatura hebrea en la España medieval, Madrid: Fundación Amigos de Sefarad, 1991, p. 228. 394

37 Ruiz García, Elisa: Los libros de Isabel la Católica. Arqueología de un patrimonio escrito, Salamanca, 2004, 


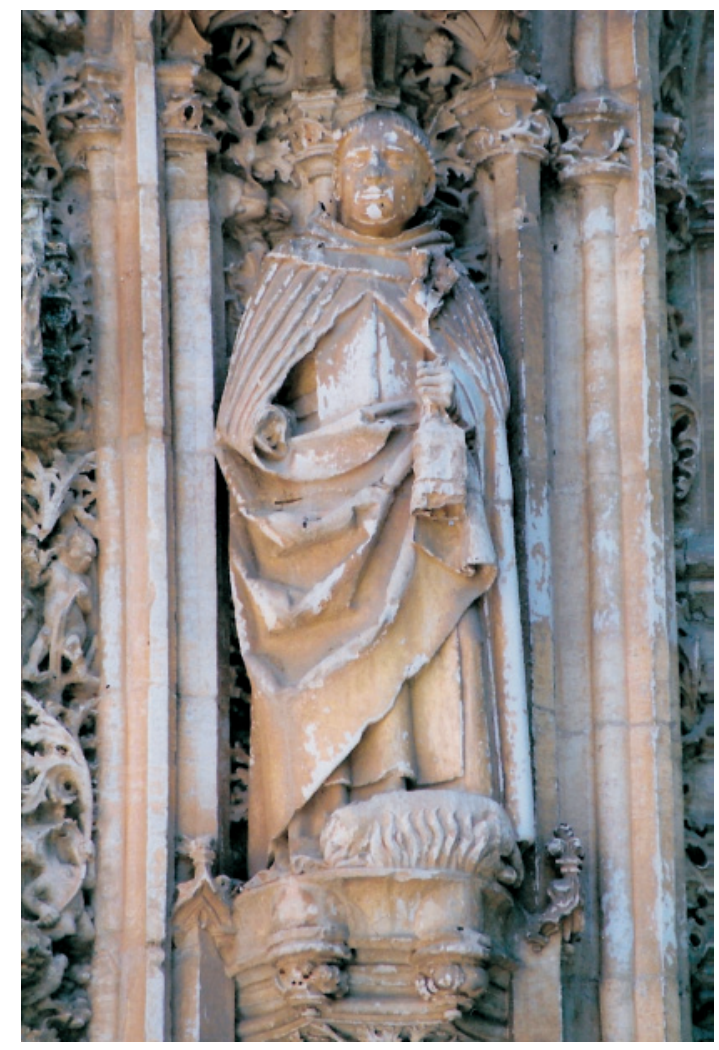

Fig. 5. Santo Domingo de Guzmán.

Portada de la iglesia del Convento de la Santa Cruz de Segovia.

contra Iudeos de Nicolaus de $\mathrm{Lyra}^{38}$, lo que nos permite hacernos una idea del alcance y difusión de los textos antihebreos, cuya área de influencia abarcaría también los ámbitos conventuales. La biblioteca del convento de Santo Tomás de Ávila debió de ser una de las mejores y más completas de la Orden. Su magnitud es destacada por el Maestro General de los dominicos Vicente Bandello, quien la visitó el 27 de mayo de 1504 decidiendo establecer aquí un Estudio General de Filosofía y Teología. Uno de los factores tenidos en cuenta a la hora de tomar esta iniciativa fue la copiosa biblioteca con la que estaba dotado el convento abulense ${ }^{39}$. Gran parte de esos libros y manuscritos se conservan en la Biblioteca Nacional de Madrid debido al intercambio realizado en el siglo XVIII entre la Biblioteca Real de Madrid y la conventual ${ }^{40}$. Iriarte, académico de la biblioteca madrileña, y un colaborador visitaron el convento realizando un inventario de su colección gracias al cual se puede comprobar la riqueza de la misma, con una importante colec-

\footnotetext{
38 Ibidem.

39 GonZÁlez, Donato O.P.: "La antigua biblioteca tomasina (I)", El Diario de Ávila, 3 de noviembre de 1993, p. 15.

40 Este intercambio de libros es conocido como la Permuta de Ávila. Debido a la existencia de una universidad en el convento, la biblioteca necesitaba nuevos y actualizados fondos para satisfacer las necesidades de sus profesores y alumnos. Por ello, el convento solicitó una serie de libros a la Biblioteca Real a cambio de Códices y manuscritos, considerados en ese momento como material inútil. Esa permuta se efectuó entre 1735 y 1737 entre el padre Escudero y el bibliotecario Blas Nasarre. Para más datos, De ANDRÉs, Gregorio: "La colección de códices del convento de Santo Tomás de Ávila en la Biblioteca Nacional. Su identificación”, Hispania Sacra, año 41, enero-junio de 1989, pp. 105-128.
} 
ción de Códices de los siglos XIV y XV ${ }^{41}$. El iniciador fue Torquemada según se desprende de la información aportada en la correspondencia establecida entre un responsable de la Biblioteca Real -hoy Nacional- y el padre Escudero, de la conventual, en el siglo XVIII, cuando tuvo lugar el intercambio de libros conocido como la Permuta de Ávila:

Quisiera dejarlo concluido por ser obra de un señor Torquemada, hijo de un convento de Valladolid, y deseo que los libros que a excesivo coste compró se pusiesen en más seguridad que aqui habrán de tener ${ }^{42}$.

Es muy probable que entre sus fondos destacara un ejemplar del Tratado del Alboraique, opúsculo de gran éxito que se seguiría editando hasta el siglo XVI, o cualquier otro texto de tintes antijudíos, como cada una de las manifestaciones artísticas dirigidas por el dominico ${ }^{43}$.

El nombre alboraique le venía del corcel que el arcángel Gabriel regaló a Mahoma sin una forma definida, sin ser caballo ni mula, macho o hembra. Alboraico fue el término que utilizó el autor para referirse a los cristianos nueuos, que no eran ni judíos ni cristianos ${ }^{44}$. En las páginas que componen este libro se describen las peculiaridades de este animal y se les aplica a los "falsos cristianos":

Alboraique tenía boca de lobo y así la tenían los marranos, pues eran hipócritas y falsos profetas. Alboraique tenía orejas de galgo, y los marranos eran perros, pues volvían a lamer el vómito de su sabbath. Comía toda clase de cosas y los marranos comían manjares moros y cristianos y nunca ayunaban... ${ }^{45}$

Debemos, pues, incluir este motivo iconográfico dentro de esa oleada de odio hacia la condición de converso, reflejada no sólo en las artes plásticas sino también en la literatura, algo que Torquemada supo utilizar de una manera eficaz para dirigir su causa ${ }^{46}$. El animal sobre el que clava la cruz Santo Domingo está inspirado en el alboraique, alegoría del falso converso y del enemigo de la fe: ... ca siendo malos et hereges de cristianos et son lobos: veyendo todos que por sus obras son lobos ${ }^{47}$. La manipulación y utilización de la imagen de un santo que apostó por un método pacífico, con el fin de apoyar la política de represión y persecución hacia los

${ }^{41}$ GonzÁlez, Donato O.P.: "El fondo de Santo Tomás de Ávila de la Biblioteca Nacional”, El Diario de Ávila, viernes 5 de noviembre de 1993, p. 15.

42 BNM. Sala Cervantes. Archivo Sign. 0440. Doc. 1. Carta de 3 de octubre de 1736.

43 En la colección que reunió Torquemada en su incipiente biblioteca, se encontraban manuscritos e impresos confiscados a judíos conversos, como es el caso de la colección de Alonso de Cota, acusado de judaizante y quemado en la hoguera en 1486. De AndRÉs, Gregorio: "La colección de códices...", op. cit., p. 111. También, FERnÁNDEZ Pomar, José M.a: "Manuscritos e incunables jurídicos de Santo Tomás de Ávila en la Biblioteca Nacional", Anuario de Historia del Derecho Español, 56, 1986, p. 867. Tal vez, un ejemplar del Alboraique pudo engrosar los fondos del convento, procedente de los bienes confiscados a algún converso acusado de judaizar. Otra posibilidad es que no tuviera el texto concreto, sino que tuviera noticias de él, por tradición oral o bien de forma indirecta por citas contenidas en otros escritos, como ocurrió con los Diálogos de Pedro Alfonso, conocidos por el lector de la época gracias a otras obras impresas, como es el caso de la Leyenda Dorada de Santiago de la Vorágine. TenA, Pedro: "Una versión...”, op. cit., p. 182.

${ }^{44}$ Hoper, Thomás: Torquemada, Buenos Aires, 1944, p. 123.

45 BNM, Sala de Manuscritos, Mss. 17.891: Historia de las comunidades de España sacada de la crónica del emperador Carlos Quinto, escrita por Pedro Mexía su cronista/Ítem libro llamado el Alboraique.

${ }^{46}$ La primera descripción del libro del Alboraique la ofreció Isabel Mateo en Temas profanos en la escultura gótica española. Sillerías de coro, Madrid, 1979, destacando la inscripción del nombre en la sillería del coro de la catedral de Sevilla, pp. 198-203.

47 Bustamante García, Agustín: “Alboraique...”, op. cit., p. 423. Nota 15. 
judíos, forma parte del intento de Torquemada por legitimar y prestigiar su política personal y la del propio Tribunal ${ }^{48}$.

Pero la imagen de Santo Domingo clavando el báculo sobre un animal híbrido de estas características es rastreable en una época anterior al establecimiento del Tribunal de la Inquisición en Castilla y Aragón. Una de las miniaturas que ilustran el mal llamado Libro de Horas de Isabel la Católica, perteneciente a Juana Enríquez, conservado en la biblioteca del Palacio Real de Madrid, representa precisamente este motivo. Santo Domingo, revestido con el hábito de su Orden, porta el libro en su condición de predicador y el tradicional báculo rematado en una cruz que clava sobre el animal, referido, bajo sus pies. Pero la escena se enriquece al situarse en el interior de un pequeño oratorio en el que es visible una mesa de altar sobre la que se dispone un cáliz, presidida por un tríptico abierto, en el que es posible identificar a la Virgen con el Niño en su hornacina central. Dos referencias al carácter humano y redentor de Cristo, de un lado la Madre, y de otro el cáliz, símbolo del martirio y el carácter salvífico de la sangre de Cristo. La misma estructura del templo, un tanto irreal si atendemos al sistema de apoyos planteado, parece sostenerse sobre las dos columnas del primer plano que flanquean a Santo Domingo, cuyos capiteles sirven de base a dos personajes; el situado a la izquierda del espectador en actitud de leer un libro y el opuesto, girado hacia él en actitud de escucha. El tocado de ambos en forma de cono, así como las túnicas y mantos, los identifica con personajes bíblicos del Antiguo Testamento, quizás profetas que anunciaron la venida del Mesías, de este modo, su ubicación a la entrada del edificio religioso les presentaría, desde el punto físico y moral, como la antesala y el sostén de los acontecimientos venideros.

A pesar de encontrarse entre las pertenencias de la reina Isabel, el Libro lo debió de heredar de su suegra D. ${ }^{a}$ Juana Enríquez, quien aparece arrodillada en distintas páginas ante la Virgen ${ }^{49}$, lo que nos indica una tradición iconográfica que se remonta a una época anterior al establecimiento de la Inquisición, caracterizada por tensiones y disputas sociales entre judíos y cristianos. La figuración de Santo Domingo como vencedor ante las herejías sería retomada por el lenguaje inquisitorial, añadiendo el detalle de las llamas en alusión al castigo recibido por los herejes, para personalizar aún más el motivo, actualizarlo y vincular directamente al santo con el Tribunal del Santo Oficio, a pesar de que ello supusiera falsificar la historia. Se recurre así, al mismo sistema recomendado por las Ars Praedicandi en el ejercicio de la predicación ${ }^{50}$, presente tanto en la literatura homilética como en los sermones pronunciados, me refiero a la utilización de similitudines, alegorías y referencias a animales para expresar determinados contenidos de una manera más accesible a un público apenas instruido ${ }^{51}$. La presencia de este motivo en un libro anterior a 1488 -fecha propuesta para la aparición del Tratado del Alboraique-, implica también una cronología temprana para la aparición de esta tradición, a pesar de que fuera extraordinariamente explotada por el Tribunal de la Inquisición, tanto en las representaciones plásticas como en el marco de las predicaciones públicas. Constituye un ejemplo más del papel de los comentarios orales de los frailes desde el púlpito como "complemento de la imaginería hoy muda"52. Contamos con ejem-

48 Otros detalles sobre el uso y abuso de la imagen de Santo Domingo en CABALLERo EsCAmilla, Sonia: "El convento de Santo Tomás de Ávila...", op. cit.

49 YARZA LuACES, Joaquín: Isabel la Católica, promotora artística, León, 2005, p. 87. Se ofrecen fotografías en color en López SerRano, Matilde (estudio preliminar): Libro de Horas de Isabel la Católica, Madrid, 1969.

50 SÁnchez SÁnchez, Manuel Ambrosio: "Los Bestiarios en la predicación castellana medieval”, Actas del III Congreso de la Asociación Hispánica de literatura medieval (Salamanca, 3-6 de octubre de 1989), Salamanca, 1994, Tomo II, pp. 915-921.

51 CÁtedra, Pedro M.: Los sermones atribuidos a Pedro Marín. Van añadidas algunas noticias sobre la predicación castellana de San Vicente Ferrer, Salamanca, 1990, p. 35. Nota 27.

52 Moralejo Álvarez, Serafín: “Artes figurativas y artes literarias en la España Medieval: románico, romance y roman", Patrimonio artístico de Galicia y otros estudios, Santiago de Compostela, 2004 (Tomo II). p. 58. Según este 
plos anteriores, numerosos en la escultura de las catedrales, en los que se representa la Sinagoga bajo el aspecto de un basilisco, es el caso del coro de la catedral de Brême ${ }^{53}$. De hecho, el animal del Libro que nos ocupa, ofrece el aspecto de un basilisco, una tradición que desembocaría, al menos en el ámbito hispano, en la identificación del judío y converso con una figura demonizada en el texto bíblico y en el contexto literario de la época, como es el lobo, buscando un mayor calado y una mayor presencia en la psicología de las masas.

Con este detalle, se alteran de nuevo los límites cronológicos emparentando a un personaje del pasado - Santo Domingo- con una situación que no llegó a conocer -la lucha contra los criptojudíos. No se duda, por tanto, en manipular la historia para que los efectos sean más favorables, toda vez que el santo acude a prestigiar la institución.

Pero Torquemada no se limita al exterior de sus fundaciones, sino que completa el mensaje en el interior, donde dispuso un conjunto de pinturas e inscripciones murales cuyo contenido no hacía sino reforzar la propaganda inquisitorial antijudía. En la arquitectura tardogótica era muy frecuente rematar los muros interiores con frisos epigráficos que contenían leyendas en consonancia con las funciones del espacio que ocupaban. Ni en Santa Cruz de Segovia ni en Santo Tomás de Ávila hemos conservado tales inscripciones, pero sí son aún visibles los frisos, teniendo además constancia documental de que no siempre estuvieron lisos. Una de las condiciones exigidas en las cláusulas del contrato del arquitecto Martín de Solórzano para realizar la Librería Capitular de la catedral de Ávila, es la inclusión de una inscripción de aspecto similar a la que recorre la iglesia de Santo Tomás, aunque de contenido diferente ${ }^{54}$. Las inscripciones se eligen en función del espacio y el uso que se le dé, por eso las librerías capitulares muestran leyendas referentes al conocimiento y a la sabiduría, como es el caso de la abulense cuyo texto está dedicado a la Sabiduría y proviene del Libro de los Proverbios. Pero, ¿a qué hacía referencia el friso de Santo Tomás? Una noticia documental del S. XIX nos informa al respecto (se refiere a Torquemada):

Desterró la herejía de aquel sagrado recinto, haciendo escribir en sus paredes: "Pestem fugat hereticam", bien lejos de creer que una mano impía osara borrar esta expresión última de su voluntad... jel testamento del pobre dominico grabado sobre las piedras de su monasterio! 55 .

En la iglesia de Santa Cruz de Segovia también hubo un friso con inscripción, del que tampoco se ha conservado resto alguno ${ }^{56}$. Pero, sin duda, el contenido no sería muy distinto al señalado para la iglesia abulense. El impacto que el ambiente ejercía sobre el público asistente no se hacía esperar, motivando la repulsa total hacia los que detentaban la condición de herejes, de la que el grupo converso era el principal sospechoso. En Santo Tomás, sede del Tribunal de la Inquisición, el nivel coercitivo era aún mayor puesto que se reforzaba con la presencia de los sambenitos colgados en los muros de su iglesia:

autor, la representación de la mujer adúltera con la cabeza del amante en su seno de la Portada de las Platerías de la catedral de Santiago de Compostela, debería interpretarse en este mismo sentido.

53 Blumenkranz, Bernhard: Le juif médiéval au miroir de l'art chrétien, París, 1966, p. 64.

${ }^{54}$ Contrato con Martín de Solórzano para la construcción de la librería capitular. (AHN. Códice 451-b. Libro de actas capitulares de la Catedral de Ávila de 1494 a 1512. F. 9.):

Yten que ençima de las represas donde han de comenzar los jarjamentos un letrero de la forma del de Santo Thomás Contrato con Martín de Solórzano para la construcción de la librería capitular.

Transcrito en Ruzz AyúCAR, M. a Jesús: "Los obispos y el arte", Cuadernos Abulenses, n. . 28, año 1999, pp. 111-115.

55 Rodrigo, Francisco Javier G.: "El vble P. Fr. Tomás de Torquemada, Inquisidor General”, Historia verdadera de la Inquisición, T. 20. Cap. 23, Madrid, 1877, pp. 110-116.

56 Carrero Santamaría, Eduardo: "El convento de Santa Cruz la Real de Segovia...”, op. cit., p. 151. 
En la Capilla Mayor de la iglesia de dicho convento de Santo Tomás, que así san benitos sirven de lienzos que ocupan los dos lienzos comenzando desde los colaterales de la Capilla hasta su remate ${ }^{57}$.

Finalmente, recurrió a uno de los mejores pintores de su época para la realización de los retablos que iban a presidir los tres altares principales de Santo Tomás y uno en Segovia, Pedro Berruguete. Quizá recurrió a él atraído por la calidad de sus obras o por su cercanía a la Orden de Predicadores y el conocimiento del lenguaje inquisitorial. No hacía muchos años, había regresado de su viaje a Italia, donde, teniendo en cuenta las influencias reflejadas en sus obras, debió de conocer en persona fundaciones como Santa María sopra Minerva, centro de reuniones del Consejo de la Inquisición para dictar las sentencias y escenario de actos relacionados con la exposición pública de los herejes, donde se depositaban, además, los sambenitos ${ }^{58}$. Por otro lado, la coincidencia de detalles del sepulcro santo representado en una de las tablas que pintó para Santo Tomás, con el monumento funerario de Santo Domingo de Guzmán en Bolonia, hizo sospechar al profesor Yarza, de la probabilidad de un viaje a esta ciudad para visitar la capilla donde descansan los restos de Santo Doming ${ }^{59}$. Tenemos motivos para pensar que estuvo también en Milán, donde conocería la capilla Portinari en la iglesia de San Eustorgio, lugar de enterramiento del inquisidor San Pedro Mártir ${ }^{60}$. Si a ello unimos la circunstancia de que su tío era dominico, comprobaremos el grado de familiaridad que tenía con la Orden.

El Cristo crucificado de Berruguete, conservado en la Diputación de Segovia pero procedente del convento de Santa Cruz, debemos incluirlo dentro del proyecto ideado por Torquemada. No sabemos el lugar que ocupó pero, dadas sus dimensiones, pudo presidir el altar mayor de la capilla que sirve de acceso a la Santa Cueva. La utilización de la imagen de Cristo en la cruz como la prueba más clara de la insidia judía está también presente en la iglesia de Santo Tomás, aunque en este caso con una imagen escultórica ${ }^{61}$. Pero, donde más claramente se reflejan los mecanismos ideados por Torquemada para lograr su objetivo es en la serie pictórica destinada a presidir los altares, mayor y del transepto, de la iglesia de Santo Tomás de Ávila, así como otras pinturas destinadas a distintos ámbitos del convento, todas, salvo una, realizadas por el pintor palentino. Las vidas de los santos efigiados en la portada, se desarrollan en distintas tablas: Santo Tomás de Aquino en el retablo mayor y Santo Domingo y San Pedro en los laterales. Pero Torquemada no eligió los pasajes al azar, sino que aprovechó aquellos momentos de sus vidas que pudieran tener una aplicación en el momento presente, como el Asesinato de San Pedro Mártir a manos de unos herejes en uno de los retablos del transepto dedicado a San Pedro de Verona o la propia imagen de Santo Domingo de Guzmán, presentado como Enquisidor en la tabla que presidía su retablo, por no hablar del conocido Auto de Fe conservado ${ }^{62}$, en el que se implica

57 Archivo del Convento de Santo Tomás de Ávila: Libro becerro 1776. Cajón n. ${ }^{\circ}$ 1, n. ${ }^{\circ} 4$.

58 Bethencourt, Francisco: La Inquisición en la época moderna: España, Portugal, Italia, siglos XV-XIX, Madrid, 1997, p. 34.

59 YARZA, Joaquín: "Una imagen dirigida...”, op. cit., p. 48.

${ }^{60}$ Algunas de sus pinturas demuestran un posible conocimiento de las pinturas murales que decoran la capilla Portinari en la iglesia de San Eustorgio de Milán, cuya decoración pictórica corrió a cargo de Vincenzo Foppa, quien realizó un ciclo de frescos dedicado a San Pedro Mártir. Vid. los comentarios al respecto en nuestra Tesis Doctoral "Las artes plásticas del s. XV en Ávila” dirigida por la profesora Lucía Lahoz y defendida el 4 de septiembre de 2007. Expresamos desde aquí nuestro agradecimiento a la Doctora Lahoz por su continua implicación en el trabajo.

${ }^{61}$ Para más detalles, Caballero Escamilla, Sonia: "El convento de Santo Tomás de Ávila: Santo Tomás de Aquino...", op. cit.

${ }^{62}$ Unos cronistas del s. XVII se refieren a la representación del primer Auto celebrado en Palencia en 1236 conservado en Santo Tomás, en el que el mismo rey San Fernando lleva un haz de leña para castigar a los herejes. No se conoce el paradero de la misma, vendida en Inglaterra según Villaamil, pero su existencia demuestra, una vez más, la 
al mismo Santo como inquisidor en ejercicio de sus funciones, tergiversando conscientemente la realidad histórica ${ }^{63}$ y demostrando que todas y cada una de las obras formaban parte de un proyecto completo e integrado.

Finalmente, en la Virgen de los Reyes Católicos Torquemada se hizo representar entre los personajes sagrados, una vez más Santo Domingo, San Pedro Mártir y Santo Tomás, junto a los Reyes Católicos y en presencia de la Virgen con el Niño. Son aquéllos, implicados de una forma directa en la persecución de las herejías, quienes cuentan con el apoyo de la divinidad ${ }^{64}$. Esta tabla servía de colofón a todo un proyecto en el que se buscó presentar a la Orden de Predicadores y a la Monarquía, como los responsables de la lucha antiherética. Utilizando el prestigio de estas dos instituciones mediante sus miembros más populares, se pretendía influir en la ideología de las masas, e incluso en la de los mismos religiosos, para lograr una única y común Confesión religiosa.

Fecha de recepción: 16-VII-2006

Fecha de aceptación: 29-IX-2006

utilización de la imagen real por parte de Torquemada, implicándola directamente en la causa inquisitorial. San Fernando actuaría como el antecesor del rey Fernando el Católico en la persecución de las herejías, del mismo modo que Santo Domingo o San Pedro de Verona en el papel de inquisidores. PINEDA, Juan de: Memorial de la excelente santidad y heroicas virtudes del senor rey Fernando tercero de este nombre..., Sevilla, 1627, p. 85; MANuEl RodríGuEZ, Miguel de: Memorias para la vida del santo rey D. Fernando III, Madrid, 1800, p. 31.

${ }^{63}$ Dispuso para ello de un Códice dedicado a la vida de los principales santos dominicos, del que conservamos una versión en el convento de Santo Domingo el Real de Madrid. Para más información, Caballero Escamilla, Sonia: "El Códice Medieval como fuente artística: Berruguete en Santo Tomás de Ávila", op. cit.

${ }^{64}$ El análisis de esta pintura en Caballero Escamilla, Sonia: "La Virgen de los Reyes Católicos: escaparate de un poder personal e institucional”, Reales Sitios, 173, 2007, pp. 20-41. 